\title{
Response of prolactin to different photoperiods after surgical disconnection of the hypothalamus and pituitary in sheep fetuses
}

\author{
D. C. Houghton ${ }^{1}$, I. R. Young ${ }^{2}$ and I. C. McMillen ${ }^{1}$ \\ ${ }^{1}$ Department of Physiology, The University of Adelaide, Adelaide SA 5005, Australia; and ${ }^{2}$ Department \\ of Physiology, Monash University, Clayton 3168, Australia
}

\begin{abstract}
The aim of this study was to determine the impact of surgical disconnection of the fetal hypothalamus and pituitary on the fetal prolactin response to different photoperiods. Disconnection of the hypothalamus (HPD) or a sham operation was carried out at around day 110 of gestation (term $=145 \pm 3$ days). Before surgery, pregnant ewes were maintained under a photoperiod of $12 \mathrm{~h}$ light:12 h dark. After surgery, ewes carrying HPD fetuses $(n=10)$ or intact fetuses $(n=13)$ were exposed to either a long day (16 h light:8 h dark) or a short day ( $8 \mathrm{~h}$ light:16 h dark) regimen until day 143 of gestation. Thyrotrophin-releasing hormone $(50 \mu \mathrm{g})$ was administered intrafetally at days $130-135$ of gestation and chlorpromazine (a dopaminergic antagonist) was administered to all sheep fetuses at days 141-142 of gestation. Mean fetal prolactin concentrations were significantly higher in the long day group (HPD: $37.3 \pm 11.3 \mathrm{ng} \mathrm{ml}^{-1}$; intact: $71.0 \pm 16.2 \mathrm{ng} \mathrm{ml}^{-1}$ ) than in the short day group (HPD: $9.0 \pm 4.8 \mathrm{ng} \mathrm{ml}^{-1}$; intact: $34.2 \pm 16.0 \mathrm{ng} \mathrm{m}^{-1}$ ). In the intact group, fetal prolactin concentrations increased significantly between day 6 and day 30 of exposure to either photoperiod. However, in the HPD group, fetal prolactin increased with increasing exposure to the long day photoperiod and decreased with increasing exposure to the short day photoperiod. The peak percentage increases in prolactin after administration of thyrotrophin-releasing hormone were significantly higher in the short day group (HPD: $696 \pm 195 \%$; intact: $521 \pm 86 \%$ ) than in the long day group (HPD: $211 \pm 13 \%$; intact: $224 \pm 26 \%$ ). There were no differences, however, between the intact and HPD groups in the percentage responses to thyrotrophin releasing hormone in either lighting regimen. In the intact group, the peak increase in prolactin occurred at $20 \mathrm{~min}$ after chlorpromazine in the short day group and at $40 \mathrm{~min}$ after chlorpromazine in the long day group. In the HPD group, there was no significant change in prolactin after chlorpromazine administration in either lighting regimen. In ewes carrying intact fetuses, maternal prolactin concentrations were significantly higher under the long day regimen than under the short day regimen. In the ewes carrying HPD fetuses, however, there was no consistent difference between maternal prolactin concentrations under either lighting regimen during the entire study period. In summary, we have demonstrated that there is a prolactin response to external photoperiod in sheep fetuses in which the hypothalamic-pituitary axis is either intact or surgically disconnected. The prolactin response is, therefore, unlikely to be entirely mediated by the inhibitory dopaminergic innervation of the pars distalis or median eminence.
\end{abstract}

\section{Introduction}

Most seasonally breeding animals show a seasonal pattern of prolactin concentrations with peak and trough concentrations occurring during long and short daylengths, respectively (Curlewis, 1992). Studies on rams have shown that the seasonal increase in prolactin secretion is closely correlated with the seasonal increase in the growth of horns and in wild, feral and some domesticated breeds of sheep with the resurgence of growth of the pelage and moulting (Lincoln, 1990). The

Received 13 December 1994. seasonal prolactin rhythm therefore plays a key role in the adaptation of sheep to the external environment. It has been shown that denervation or removal of the pineal gland in sheep reduces or blocks photoperiod-induced changes in prolactin (Barrell and Lapwood, 1979; Brown and Forbes, 1980; Maxwell et al., 1989). Furthermore, timed administration of melatonin to ewes under long photoperiods has been shown to decrease prolactin concentrations (Kennaway et al., 1982; Poulton et al., 1986). It is considered, therefore, that the duration of the nocturnal peak in melatonin secretion regulates prolactin secretion in sheep. 
It has also been shown that although sheep fetuses are not directly exposed to light in utero, seasonal changes in photoperiod are associated with changes in fetal plasma concentrations of prolactin (Bassett et al., 1988; Seron-Ferre et al., 1989). As prolactin does not cross the ovine placenta, this implies that the fetal hypothalamic-pituitary axis is sensitive to changes in the external photoperiod. It has been shown that there is a diurnal rhythm in plasma melatonin concentrations in fetal lambs and pregnant ewes during late gestation (Yellon and Longo, 1987; Zemdegs et al., 1988). It has also been shown that melatonin crosses the sheep placenta and that pinealectomy of pregnant ewes abolishes the daily rhythm in maternal and fetal melatonin concentrations throughout late gestation (Yellon and Longo, 1988; Zemdegs et al., 1988; McMillen and Nowak, 1989). Fetal concentrations of prolactin increase after pinealectomy of pregnant ewes (McMillen et al., 1991) and when melatonin is infused into intact pregnant ewes during summer pregnancies to simulate the winter duration of the nocturnal melatonin increase, there is an associated reduction in the fetal and maternal plasma concentrations of prolactin (Bassett et al., 1989). It is clear, therefore, that the duration of the nocturnal melatonin signal provides the adult and fetal sheep with photoperiodic information. The neuroendocrine changes that link melatonin to synthetic or secretory changes in fetal pituitary lactotrophs are poorly understood. Lincoln and Clarke (1994) reported that photoperiodic regulation of prolactin secretion was maintained in adult rams in which the pituitary gland was functionally isolated from the brain. It has also been shown that there are exceptionally high concentrations of iodomelatonin-binding sites on the cells of the ovine pars tuberalis (Morgan et al., 1989). The pars tuberalis consists of multilayered strands of glandular epithelium surrounding the hypophysial stalk and extending along the ventral surface of the median eminence (Wittkowski et al., 1992). The high concentrations of melatonin-binding sites outside the ovine hypothalamus prompted us to investigate whether there are differences in fetal plasma concentrations of prolactin in ewes held in long and short external photoperiods after surgical disconnection of the fetal hypothalamus and fetal pituitary.

\section{Materials and Methods}

\section{Animals and surgery}

All experimental procedures in this study received approval from the University of Adelaide Standing Committee on Ethics in Animal Experimentation. Twenty-three pregnant Merino ewes were used, and the study was carried out between April and September (autumn and early spring in the Southern Hemisphere). Merino ewes were used because there is evidence indicating that they have a robust prolactin response to seasonal changes in photoperiod (Lincoln, 1990). All ewes were housed in a central animal holding facility and were maintained under a $12 \mathrm{~h}$ light:12 h dark cycle (lights off at 19:00 h) from at least 70 days of gestation (calculated from the date of mating) until surgery. Surgery was performed between 106 and 120 days gestation under general anaesthesia using halothane $(0.5-4.0 \%)$ and $\mathrm{N}_{2} \mathrm{O}: \mathrm{O}_{2}(50: 50, \mathrm{v}: \mathrm{v})$ with aseptic techniques. Hypothalamic-pituitary disconnection (HPD) was performed in the fetuses of ten ewes (HPD group) as described in full by Antolovich et al. (1990). A midline incision was made in the fetal nose and the nasal bone opened just left of the intranasal septum. The fetal ethmoid and presphenoid bones were drilled to form a paramedian tunnel beneath the anterior cranial fossa. The optic chiasma was located and exposed to allow access to the median eminence. The neural tissue of both internal and external laminae of the median eminence was removed using gentle suction. A small piece of gelfoam soaked in thrombin (Thrombostat; Parke-Davis, Caringbah, NSW) and penicillin (Depomycin; Intervet, Lane Cove, NSW) was introduced to separate the remaining hypothalamic tissue from the pituitary. A sham procedure was carried out in 12 sheep fetuses (intact group) in which either full cranial dissection was performed but no neural tissue was removed (25\% of group) or in which no cranial dissection was carried out (75\% of the group). The extent of the cranial dissection in the intact group did not correlate with any of the changes in prolactin measured in the subsequent experiments and so data from all animals in the intact group were combined. Catheters were inserted into a fetal and maternal carotid artery and jugular vein, and into the amniotic cavity in all ewes. All catheters were filled with heparinized saline and the fetal catheters were exteriorized via an incision in the ewe's flank.

\section{Experimental design}

After surgery, all ewes were housed in metabolic cages and fed alfalfa chaff ( $1 \mathrm{~kg}$ ) once a day between 09:00 and 11:00 h, with water available ad libitum. Six ewes in the HPD group and six ewes in the intact group were moved immediately after surgery into a long day regimen ( $16 \mathrm{~h}$ light: $8 \mathrm{~h}$ dark; lights on at $07: 00 \mathrm{~h}$ ) until day 143 of gestation or term (145 \pm 3 days gestation). Four ewes in the HPD group and seven ewes in the intact group were moved immediately after surgery into a short day regimen ( $8 \mathrm{~h}$ light:16 h dark; lights on at 07:00 h) until day 143 of gestation or term. Under the short day regimen, two ewes carried twin fetuses in the intact and HPD groups. Under the long day regimen, two ewes carried twin fetuses in the intact group and four ewes carried twin fetuses in the HPD group.

\section{Blood sampling protocol}

There was at least 6 days between surgery and the collection of the first blood sample. Maternal $(5 \mathrm{ml})$ and fetal $(2 \mathrm{ml})$ arterial blood samples were collected three times a week at 09:00-12:00 h until day 142 of gestation or term. Fetal arterial blood samples $(0.6 \mathrm{ml})$ were also collected for blood gas and $\mathrm{pH}$ analysis with an ABL 330 acid base analyser and OSM 2 haemoximeter.

Thyrotrophin-releasing hormone (TRH; Protirelin, Cambridge Laboratories, Newcastle-upon-Tyne; $50 \mu \mathrm{g}$; 15-25 $\mu \mathrm{g} \mathrm{kg}^{-1}$ ) was administered i.v. to all sheep fetuses at days 130-135 of gestation. Chlorpromazine (CPZ; Largactil, Melbourne; $12.5 \mathrm{mg}^{4} 4-6 \mathrm{mg} \mathrm{kg}^{-1}$ ) was also administered i.v. to all sheep fetuses at days 141-142 of gestation. Fetal arterial or venous blood ( $1.5 \mathrm{ml}$ ) samples were collected at $-30,-5$, $+10,+20,+40,+60$ and +120 min relative to the time of 
administration of either TRH or chlorpromazine. All blood samples were collected into heparinized tubes which were centrifuged for $10 \mathrm{~min}$ at $1100 \mathrm{~g}$ before separation and storage of plasma at $-20^{\circ} \mathrm{C}$ for assay.

\section{Prolactin radioimmunoassay}

Plasma prolactin was measured using rabbit anti-ovine prolactin (antiserum batch number AFP 973269, generously donated by the National Hormone and Pituitary Program, NIDDK, Baltimore, MD) and an assay previously described and validated by McMillen et al. (1987). The sensitivity (defined as the dose required to produce 10\% displacement) of the assay was $0.1 \mathrm{ng}$ per tube and the inter- and intra-assay coefficients of variation were $<20 \%$ and $<10 \%$, respectively.

\section{Statistical analyses}

All results are expressed as means \pm SEM. Where the Cochrans and Bartlett-Box tests identified significant heterogeneity of variance, values for maternal and fetal hormone concentrations were logarithmically transformed before further statistical analysis. The data were analysed using the Statistical Package for Social Scientists (SPSS Inc., Chicago, IL) and a VAX mainframe computer using a multifactorial analysis of variance (ANOVA) with treatment (HPD or intact group), environment (long or short photoperiod), number of days in the lighting regimen (in 4 day blocks: $6-10$ days, 11-14 days, 15-18 days, 19-22 days, $23-26$ days and 27-30 days in the long or short day lighting regimen) and animal as the specified variables. Prolactin responses to TRH and chlorpromazine were also expressed as a percentage change from baseline (baseline values were taken as the mean of the concentrations in the 30 min before administration of either TRH or chlorpromazine). ANOVAs were used to determine whether there were significant changes in prolactin concentrations or in the percentage change from baseline in the TRH or chlorpromazine experiments with treatment (HPD or intact), environment (long or short photoperiod), time $(-30,-5,+10,+20,+40$, +60 and +120 min relative to time of drug administration) and animal as the specified variables. Where the multifactorial ANOVAs identified significant interactions between major factors, the data were split on the basis of the interaction and reanalysed. When the ANOVAs indicated there were differences between groups, Duncan's post-hoc test was used to identify significant differences between mean values. $P \leq 0.05$ was taken to be significant.

\section{Results}

\section{Fetal health and outcome}

The mean values for arterial blood $\mathrm{pH}(7.37 \pm 0.001), \mathrm{Pa}_{\mathrm{O}_{2}}$ $(23.4 \pm 0.3 \mathrm{~mm} \mathrm{Hg}), \mathrm{Pa}_{\mathrm{CO}_{2}}(47.0 \pm 0.3 \mathrm{~mm} \mathrm{Hg}), \mathrm{O}_{2}$ saturation $(70.8 \pm 0.8 \%)$ and haemoglobin concentration $(9.4 \pm 0.1 \mathrm{~g}$ $\mathrm{dl}^{-1}$ ) for the blood samples collected throughout late gestation in the HPD group were within the normal range for sheep fetuses. Similarly, the mean values for arterial blood $\mathrm{pH}$

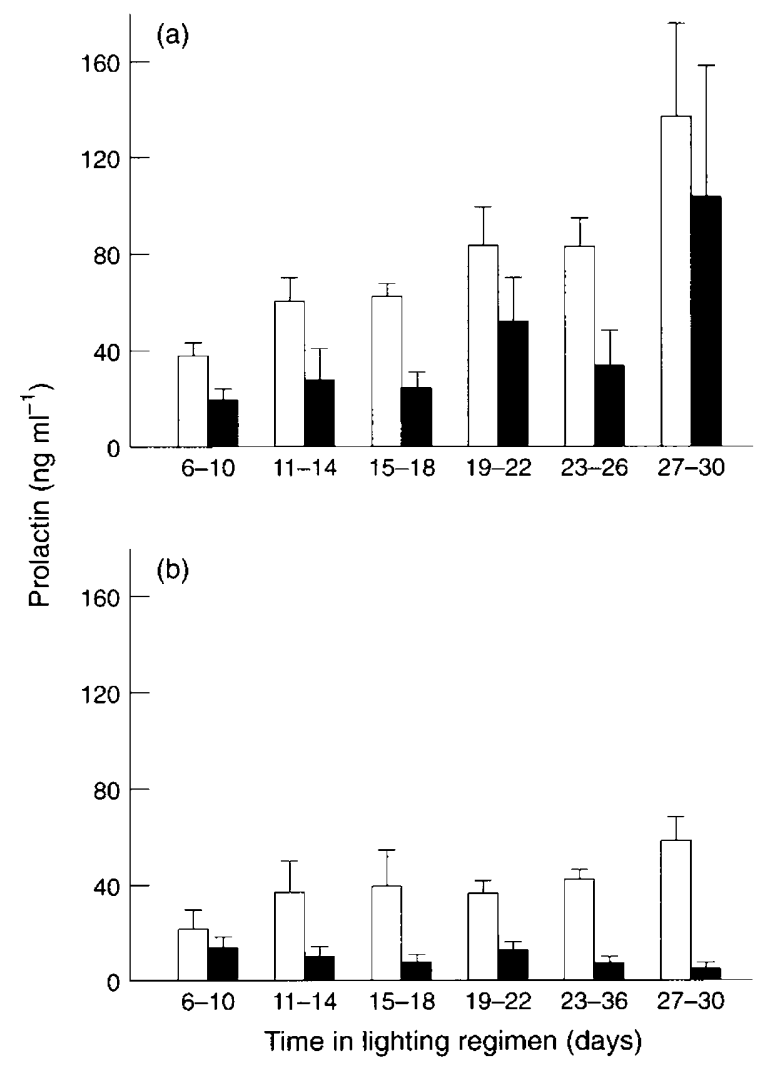

Fig. 1. Plasma concentrations of prolactin (mean \pm SEM) in (a) intact fetal sheep and (b) fetal sheep that had undergone hypothalamicpituitary disconnection during 6-30 days exposure to ( $\square$ ) long day photoperiod or ( $\boldsymbol{\square}$ ) short day photoperiod.

(7.37 \pm 0.001$), \mathrm{Pa}_{\mathrm{O}_{2}}(21.6 \pm 0.3 \mathrm{~mm} \mathrm{Hg}), \mathrm{Pa}_{\mathrm{CO}_{2}}(46.0 \pm 0.3 \mathrm{~mm}$ $\mathrm{Hg}), \mathrm{O}_{2}$ saturation $(68.1 \pm 0.9 \%)$ and haemoglobin concentration $\left(9.9 \pm 0.2 \mathrm{~g} \mathrm{dl}^{-1}\right)$ for fetal sheep in the intact group were also within the normal range. All ewes were killed between day 141 and day 143 of gestation. The mean fetal masses at post mortem were $4.2 \pm 0.2 \mathrm{~kg}$ and $4.3 \pm 0.1 \mathrm{~kg}$ in the HPD and intact groups, respectively.

\section{Prolactin concentrations in fetal plasma}

Prolactin concentrations in fetal plasma were significantly lower $(P<0.04)$ in the HPD group than in the intact group and this effect was present in both lighting regimens throughout the period of the study (Fig. 1a, b). Fetal plasma concentrations of prolactin were significantly higher $(P<0.001)$ in the long day than in the short day regimen and this effect was present in both the HPD and intact groups, that is, there was no significant interaction between the effect of surgical treatment and the effect of the light regimens on prolactin concentrations. Mean fetal plasma concentrations of prolactin in the HPD group were significantly higher $(P<0.03)$ under the long day regimen $\left(37.3 \pm 11.3 \mathrm{ng} \mathrm{ml}^{-1} ; n=6\right)$ than under the short day regimen $\left(9.0 \pm 4.8 \mathrm{ng} \mathrm{ml}^{-2} ; n=4\right)$ throughout the entire study period. Similarly, mean fetal plasma concentrations of prolactin in the intact group were significantly higher $(P<0.03)$ under the long day regimen $\left(71.0 \pm 16.2 \mathrm{ng} \mathrm{ml}^{-1} ; n=6\right)$ than under 

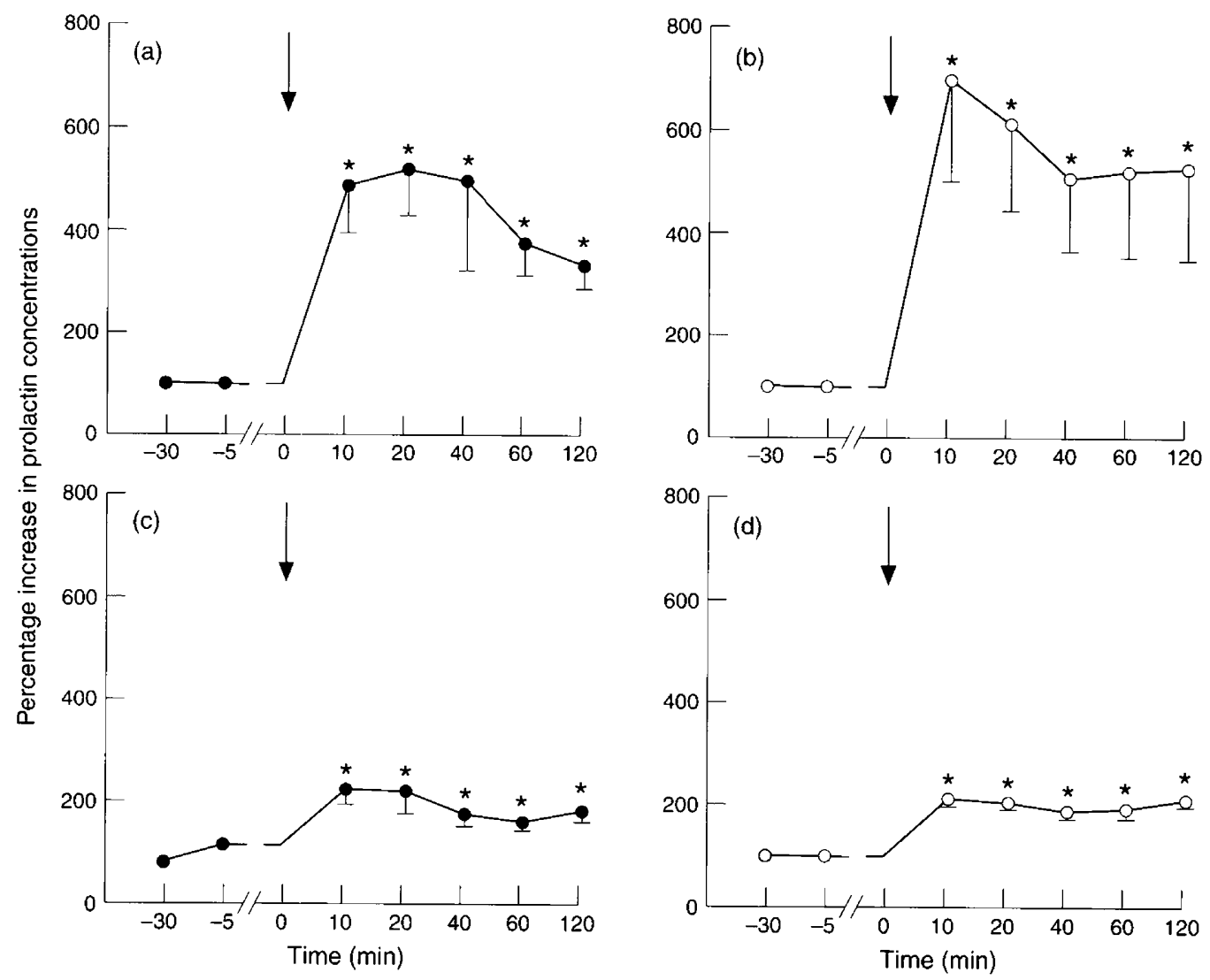

Fig. 2. The percentage increase in fetal prolactin concentrations (mean \pm SEM) after administration of $50 \mu \mathrm{g}$ thyrotrophin-releasing hormone to $(a, c)$ intact sheep fetuses and $(b, d)$ sheep fetuses that had undergone hypothalamic-pituitary disconnection during ( $a, b)$ short day photoperiods or ( $c, d)$ long day photoperiod. Thyrotrophin-releasing hormone was administered as a bolus at time zero (arrow). Asterisks denote mean values in the same treatment group and lighting regimen that are significantly different $(P<0.05)$ from baseline values.

the short day regimen $\left(34.2 \pm 16.0 \mathrm{ng} \mathrm{ml}^{-1} ; n=7\right)$ throughout the study. However, there was a significant interaction $(P<0.01)$ between the effects of treatment, light regimen and duration of exposure to the light regimen on fetal prolactin concentrations. In the intact sheep fetuses there was a significant increase $(P<0.001)$ in prolactin concentrations in both the long day and short day regimens with increasing exposure to the regimen (Fig. Ia). In this group, fetal prolactin concentrations increased progressively between 6-10 days exposure $\left(38.3 \pm 5.1 \mathrm{ng} \mathrm{ml}^{-1}\right.$ ) and $27-30$ days exposure (137.1 \pm $38.7 \mathrm{ng} \mathrm{ml}^{-1}$ ) to long days and from $19.2 \pm 4.4 \mathrm{ng} \mathrm{ml}^{-1}$ to $104.3 \pm 57.2 \mathrm{ng} \mathrm{ml}^{-1}$ during the same period of exposure to the short day regimen. However, in the HPD group there was a significant interaction $(P<0.001)$ between the effects of the duration of exposure to the light regimen and the light regimen on prolactin concentrations. In this group, prolactin concentrations in fetal plasma increased $(P<0.001)$ with increasing exposure to long days and decreased $(P<0.001)$ with increasing exposure to short days (Fig. Ib). In the long day regimen, fetal prolactin concentrations in the HPD fetal sheep increased from $21.3 \pm 7.3 \mathrm{ng} \mathrm{ml}^{-1}$ after 6-10 days exposure to $57.8 \pm 9.8 \mathrm{ng} \mathrm{ml}^{-1}$ after $27-30$ days exposure. In the short day regimen, however, the fetal plasma prolactin concentrations decreased from $13.2 \pm 4.4 \mathrm{ng} \mathrm{ml} \mathrm{m}^{-1}$ to $4.2 \pm 2.7 \mathrm{ng} \mathrm{ml}^{-1}$ over the same period.

\section{Prolactin responses to $T R H$}

There was a significant increase $(P<0.001)$ in plasma concentrations of prolactin after administration of TRH in the intact and HPD groups for both lighting regimens (Fig. 2). Plasma concentrations of prolactin, before, during and after administration of TRH were significantly higher $(P<0.005)$ under the long day than under the short day regimen in the intact and HPD sheep fetuses. Under the long day regimen, prolactin increased from $65.2 \pm 8.7 \mathrm{ng} \mathrm{ml}^{-1}(-5 \mathrm{~min})$ to $118.6 \pm 10.4 \mathrm{ng} \mathrm{ml}^{-1}$ (10 min after TRH) in the intact group and from $27.2 \pm 4.8 \mathrm{ng} \mathrm{ml}^{-1}$ ( $\left.-5 \mathrm{~min}\right)$ to $55.9 \pm 7.1 \mathrm{ng} \mathrm{ml}^{-1}$ (10 min after TRH) in the HPD group. Under the short day regimen, prolactin increased from $20.2 \pm 8.6 \mathrm{ng} \mathrm{ml} \mathrm{ml}^{-1}$ $(-5 \mathrm{~min})$ to $83.9 \pm 36.6 \mathrm{ng} \mathrm{ml}^{-1}(10 \mathrm{~min}$ after TRH) in the intact group and from $7.8 \pm 4.0 \mathrm{ng} \mathrm{m} \mathrm{m}^{-1}(-5 \mathrm{~min})$ to $45.4 \pm 29.5 \mathrm{ng} \mathrm{ml}^{-1}$ (10 min after TRH) in the HPD group. However, the percentage increases in prolactin concentrations after administration of TRH in the intact and HPD groups were significantly greater $(P<0.001)$ under the short day than under the long day regimen (Fig. 2). The peak percentage increases in prolactin concentrations were $521 \pm 86 \%, 20 \mathrm{~min}$ after TRH treatment in the intact group (Fig. 2a) and $696 \pm 195 \%, 10 \mathrm{~min}$ after treatment in the HPD group (Fig. 2b) under the short day regimen. Under the long day regimen, peak increases were 

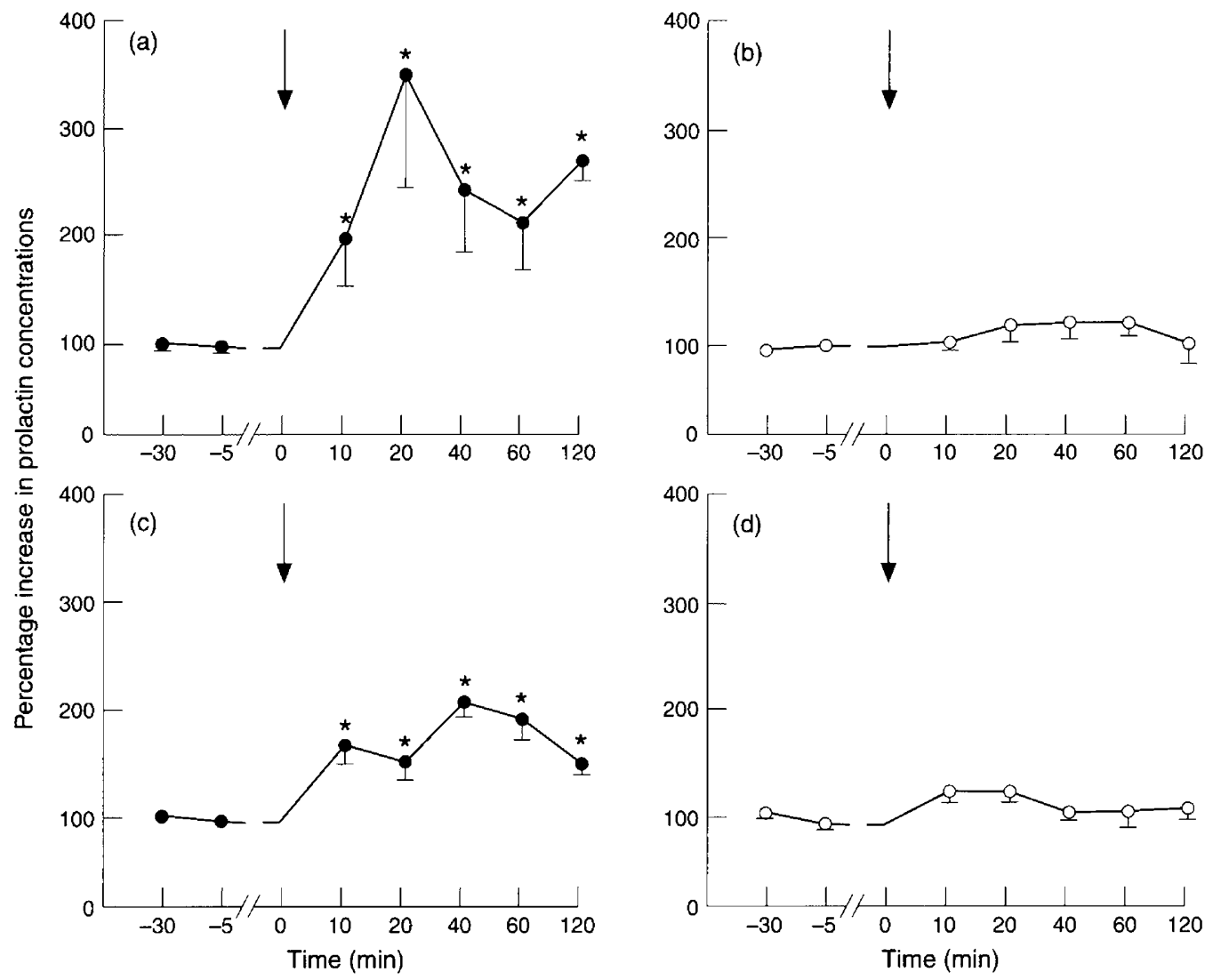

Fig. 3. The percentage increase in fetal prolactin concentrations (mean \pm SEM) after administration of $12.5 \mathrm{mg}$ chlorpromazine to $(a, c)$ intact sheep fetuses and $(b, d)$ sheep fetuses that had undergone hypothalamic-pituitary disconnection under ( $a, b)$ short day photoperiods or (c, d) long day photoperiods. Chlorpromazine was administered as a bolus at time zero (arrow). Asterisks denote mean values in the same treatment group and lighting regimen that are significantly different $(P<0.05)$ from baseline values.

$224 \pm 26 \%$, 10 min after treatment in the intact group (Fig. 2c) and $211 \pm 13 \%$, 10 min after treatment in the HPD group (Fig. 2d). There were no differences between the intact and HPD groups in the percentage responses to TRH or in the time profiles of the prolactin responses to TRH in either of the two light regimens.

\section{Prolactin responses to chlorpromazine}

There was a significant difference $(P<0.001)$ between the intact and HPD groups in the fetal prolactin response to chlorpromazine (Fig. 3). In the intact group under the long day regimen, prolactin concentrations increased after chlorpromazine from $70.0 \pm 2.3 \mathrm{ng} \mathrm{ml}^{-1}(-5 \mathrm{~min})$ to $150.1 \pm 12.4 \mathrm{ng}$ $\mathrm{ml}^{-1}(+40 \mathrm{~min})$ and $140.6 \pm 16.8 \mathrm{ng} \mathrm{ml}^{-1}(+60 \mathrm{~min})$. Under the short day regimen, prolactin increased after chlorpromazine treatment from $29.3 \pm 11.4 \mathrm{ng} \mathrm{ml} \mathrm{m}^{-1}(-5 \mathrm{~min})$ to $85.4 \pm$ $29.3 \mathrm{ng} \mathrm{ml}^{-1}$ ( $+20 \mathrm{~min}$ ) and $71.1 \pm 30.3 \mathrm{ng} \mathrm{ml}^{-1}$ (+ $\left.40 \mathrm{~min}\right)$. However, when this response was expressed as a percentage increase from baseline, there was no difference in the prolactin response to chlorpromazine between the two light regimens. The time profile of the prolactin response was different $(P<0.05)$ between the long day and short day regimens in the intact sheep fetuses, with the peak increase in prolactin occurring $40 \mathrm{~min}$ after chlorpromazine administration under the long day regimen, whereas the peak increase occurred $20 \mathrm{~min}$ after chlorpromazine under the short day regimen. In the HPD group, there was no significant change in plasma concentrations of prolactin after chlorpromazine administration in either the long day or the short day regimens. Plasma prolactin concentrations were $36.0 \pm 6.6 \mathrm{ng} \mathrm{ml}^{-1}(-5 \mathrm{~min})$ before chlorpromazine administration and $44.9 \pm 6.2 \mathrm{ng} \mathrm{ml}^{-1} 20 \mathrm{~min}$ after chlorpromazine treatment in the long day regimen and $5.6 \pm 2.8 \mathrm{ng} \mathrm{ml}^{-1}(-5 \mathrm{~min}$ ) before chlorpromazine and $6.0 \pm 3.1 \mathrm{ng} \mathrm{ml} \mathrm{ml}^{-1} 10 \mathrm{~min}$ after chlorpromazine in the short day regimen. In the HPD group, plasma prolactin concentrations before, during and after chlorpromazine were higher in the long day regimen than in the short day regimen.

\section{Maternal plasma concentrations of prolactin}

There was a significant interaction $(P<0.02)$ between the effects of the light regimen, the duration of exposure to the light regimen and surgical treatment on maternal plasma concentrations of prolactin. In ewes with intact fetuses, prolactin concentrations were higher $(P<0.03)$ in the long day regimen than in the short day regimen throughout the study period. Maternal prolactin concentrations in the group 


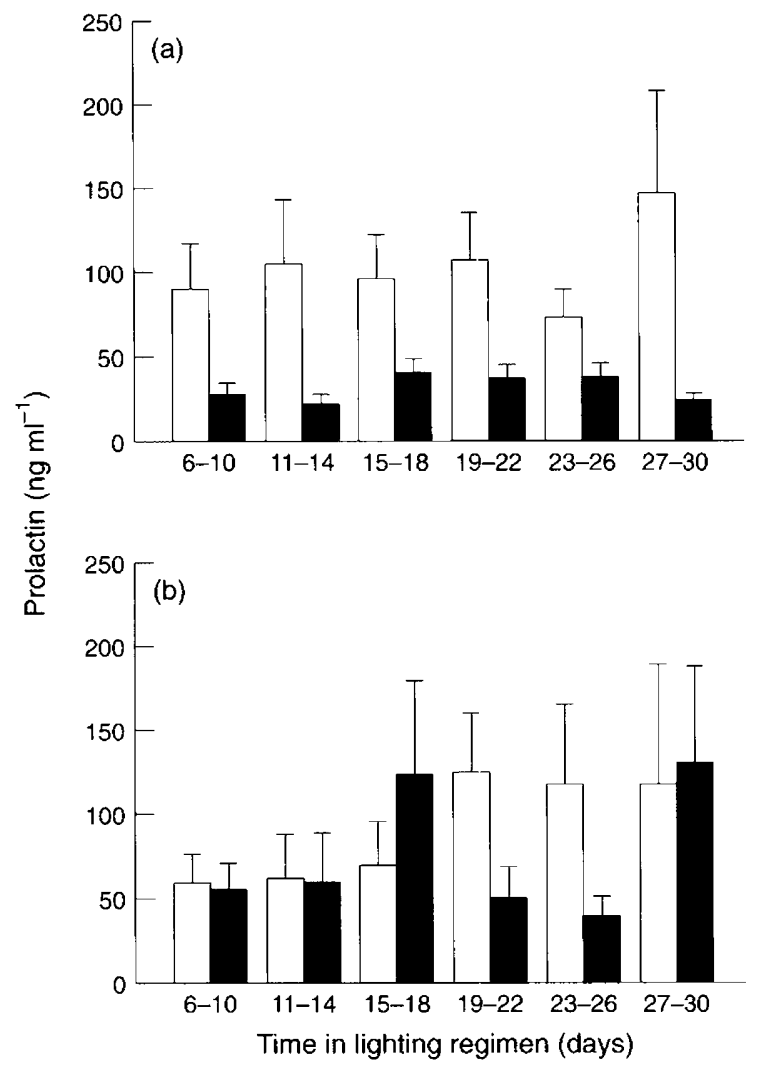

Fig. 4. Plasma prolactin concentrations (mean \pm SEM) in pregnant ewes carrying (a) intact fetuses or (b) carrying fetuses that had undergone hypothalamic-pituitary disconnection during 6-30 days exposure to $(\square)$ long day photoperiods or $(\boldsymbol{\square})$ short day photoperiods.

with intact fetuses were $90.7 \pm 26.9 \mathrm{ng} \mathrm{ml}^{-1}$ and $28.2 \pm$ $5.2 \mathrm{ng} \mathrm{ml}^{-1}$ after 6-10 days in the long day and short day regimen, respectively (Fig. 4). In the ewes carrying fetuses with HPD, there was no difference in maternal prolactin concentrations in the long day and the short day regimens when compared across the entire study period. However, there was a significant interaction $(P<0.02)$ in this group between the effects of the different light regimens and the duration of exposure to the light regimen. Maternal prolactin concentrations in the long day regimen significantly increased $(P<0.05)$ from $57.9 \pm 18.0 \mathrm{ng} \mathrm{ml}^{-1}$ after $6-10$ days exposure to $124.3 \pm 35.2 \mathrm{ng} \mathrm{ml}^{-1}$ after 19-22 days exposure and remained at $117.3 \pm 72.2 \mathrm{ng} \mathrm{ml}^{-1}$ after $27-30$ days exposure to this lighting regimen (Fig. 4a). Maternal prolactin concentrations in the short day regimen were variable and showed no consistent change throughout the study period. In this group of ewes, the maximum differences in maternal prolactin concentrations in the two light regimens occurred 19-26 days after exposure to each light regimen.

\section{Discussion}

We have demonstrated that plasma concentrations of prolactin are higher in sheep fetuses exposed to long photoperiods compared with those exposed to short photoperiods regardless of whether the hypothalamic-pituitary axis is intact or surgically disconnected but that the increase in prolactin concentration after administration of TRH is proportionally greater in sheep fetuses exposed to short external photoperiods.

In the present study, fetal plasma concentrations of prolactin were significantly lower after hypothalamic-pituitary disconnection in both lighting regimens. There was a consistent difference of about $25-35 \mathrm{ng} \mathrm{ml}^{-1}$ in plasma prolactin concentrations measured in the HPD and intact groups and this difference was similar in each light regimen. Thomas et al. (1986) demonstrated that circulating prolactin concentrations were transiently increased after HPD in adult ewes and then declined. These authors suggested that it was unlikely that the decrease in prolactin after HPD was due to pituitary infarction or to depletion of prolactin stores since the prolactin responses to TRH 190 days after HPD were similar to those seen in control animals. Lincoln and Clarke (1994) found that plasma concentrations of prolactin in rams were higher during the 17 months after HPD than in control animals. These authors concluded that, in adult sheep, prolactin secretion may be under the control of both hypothalamic release and releaseinhibiting factors.

It was shown that surgical disconnection of the fetal pituitary from the hypothalamus does not alter the morphology, distribution or proportion of the lactotrophs in the pars distalis (Antolovich et al., 1990), and it therefore seems reasonable to conclude that after HPD in fetal sheep there is a loss of a predominantly stimulatory drive to prolactin secretion. This loss may be a result of the lack of a hypothalamic prolactin-releasing factor after HPD. Alternatively, there may be loss of a placental signal that normally stimulates prolactin secretion from the fetal pituitary and that depends on the presence of a functional connection between the fetal hypothalamus and pituitary.

It was shown that there is a seasonal variation in plasma prolactin concentrations in fetal sheep during late gestation (Bassett et al., 1988; Seron-Ferre et al., 1989). We reported that fetal concentrations of prolactin increase after maternal pinealectomy and Bassett et al. (1988) found that during summer pregnancies, fetal concentrations of prolactin decreased when ewes were given an infusion of melatonin for $14 \mathrm{~h}$ each night to simulate the winter duration of the nocturnal increase in plasma melatonin (Bassett et al., 1989; McMillen et al., 1991). The main source of the circadian rhythm in plasma concentrations of melatonin in sheep fetuses is the maternal pineal gland (Yellon and Longo, 1988; McMillen and Nowak, 1989). It appears, therefore, that in sheep fetuses, as in adult sheep, the seasonal variation in fetal prolactin is related to the seasonal change in the duration of the nocturnal increase in maternal and, hence, fetal melatonin concentrations. In the present study, a relationship was found between the duration of the external photoperiod and prolactin concentrations throughout late gestation in sheep fetuses in which the fetal pituitary was disconnected from the fetal hypothalamus. These results are in agreement with those of Lincoln and Clarke (1994) who demonstrated that there was photoperiodic regulation of prolactin secretion in HPD rams in which the pituitary gland was functionally isolated from the brain. These authors also demonstrated that administration of melatonin to HPD rams under long days suppressed circulating prolactin to values observed in HPD rams under short days. Thus, it appears that 
in sheep, changes in the external photoperiod and in the duration of the nocturnal increase in melatonin concentrations regulate pituitary prolactin secretion by an extrahypothalamic mechanism before and after birth.

In the study reported here, the fetal prolactin response to treatment with TRH was similar in the HPD and intact groups. The prolactin response in both groups was significantly greater in the long photoperiod but the proportional change in prolactin from baseline concentrations was significantly higher in the short photoperiod. Such differences with prevailing photoperiod in the prolactin responses to TRH have been reported in intact fetal sheep (Bassett et al., 1989). Although it is possible that there is an increased sensitivity of the pituitary lactotroph to TRH during short photoperiods, it is equally possible that there is a proportionally greater pool of prolactin available for stimulated secretion in the lactotrophs when basal secretion is low. Our data indicate that these photoperiod-induced changes in the responsiveness to thyrotrophin-releasing hormone can occur in pituitaries that have been functionally isolated from the hypothalamus.

In most species, the major prolactin inhibitory factor is considered to be dopamine and it was proposed that the low prolactin concentrations measured during short daylengths are due to increased dopaminergic suppression of prolactin release from the lactotroph (Curlewis, 1992). Although we found no evidence for an overall increase in the proportional response of fetal prolactin to chlorpromazine during the short light regimen in the intact group, there was a difference between the time profiles of the fetal prolactin response to chlorpromazine in the two light regimens. The peak prolactin response occurred earlier under the short day than under the long day regimen. The important finding of this study is that, although there was a relationship between the fetal plasma concentrations of prolactin and the external photoperiod in the HPD group, there was no prolactin response to chlorpromazine. This clearly indicates that in the HPD group, there was no influence of dopamine, either extrahypothalamic or derived from the median eminence or posterior pituitary on prolactin secretion in either light regimen. This finding suggests that the effects of external photoperiod and changes in maternal melatonin on fetal prolactin secretion are not entirely mediated via changes in dopaminergic inhibition of pituitary function acting through the hypothalamus.

One possible extrahypothalamic site of action of melatonin is the pars tuberalis of the fetal pituitary. There is considerable indirect evidence that the pars tuberalis may be important in mediating seasonal reproductive responses to melatonin. In all mammalian groups, this tissue, unlike the pars distalis, contains exceptionally high concentrations of iodomelatonin-binding sites (Krause and Dubocovich, 1990). Most types of secretory cell in the ovine pars tuberalis are agranular and it appears that these cells are melatonin responsive (Morgan et al., 1991). A secretory product of the fetal pars tuberalis may therefore influence prolactin synthesis and secretion in the pars distalis, and the output of this product may be inversely related to the duration of the nocturnal surge of maternal melatonin concentrations.

It was interesting that, in the study reported here, there was a difference in the late gestational profiles of fetal prolactin in the intact and HPD groups. Fetal concentrations of prolactin increased with increasing exposure to long days in sheep fetuses with either an intact or disconnected hypothalamicpituitary axis. However, in intact fetal sheep, there was also an increase in fetal prolactin concentrations in late gestation under the short day regimen and this increase did not occur in the HPD group. One explanation may be that under short day conditions, there is an increase in fetal prolactin concentrations that is related to increasing gestational age, rather than to increasing exposure to short days, and that this effect depends on the presence of an intact hypothalamic-pituitary axis. Under long days, the gestational age-related increase in fetal prolactin may be masked by the separate effects of increasing exposure to long days on prolactin secretion. Merei et al. (1993) reported that there is a gestational age-related increase in abundance of mRNA encoding prolactin in the anterior pituitary of sheep fetuses maintained under the same photoperiodic conditions; this finding provides evidence for a separate influence of gestational age on fetal prolactin secretion. It is possible that disconnection of the fetal hypothalamus and pituitary alters the circulating profile of oestrogens and, hence, prolactin in late gestation.

Although there was a clear effect of external photoperiod on maternal prolactin concentrations in ewes carrying intact fetuses, this effect was not consistent in ewes carrying HPD fetuses. Bassett et al. (1989) showed that, in a group of ewes in late pregnancy, maternal prolactin concentrations did not decrease during an 8 day infusion of melatonin $\left(14 \mathrm{~h}_{\text {day }}{ }^{-1}\right)$, whereas there was an effect of melatonin on fetal prolactin during this short infusion period. The lack of a consistent difference in prolactin concentrations between the two photoperiods in ewes carrying HPD fetuses appeared to be a consequence of the increased variability of the circulating prolactin concentrations during the short day conditions. There are a number of factors that might contribute to this variability in prolactin secretion, including maternal stress and variations in circulating oestrogen concentrations.

In summary, we have demonstrated that plasma concentrations of prolactin are higher under long day external photoperiods than under short day external photoperiods in sheep fetuses in which the hypothalamic-pituitary axis is either intact or surgically disconnected. We also showed that the increase in prolactin concentrations after administration of TRH is proportionally greater under short day rather than long day external photoperiods in sheep fetuses with an intact or disconnected hypothalamic-pituitary axis.

The authors are greateful for the financial support provided by the Australian Research Council for these studies. D. C. Houghton acknowledges the receipt of a Commonwealth Postgraduate Research Award during the conduct of this research. The authors are particularly grateful to F. Carbone, S. Fielke and A. Jurisevic for expert assistance with the surgical and laboratory procedures associated with these studies.

\section{References}

Antolovich GC, Clarke IJ, McMillen IC, Perry RA, Robinson PM, Silver M and Young IR (1990) Hypothalamo-pituitary disconnection in the fetal sheep Neuroendocrinology 51 1-9 
Barrell GK and Lapwood KR (1979) Effects of pinealectomy on the secretion of luteinizing hormone, testosterone and prolactin in rams exposed to various lighting regimens Journal of Endocrinology 80 397-405

Bassett JM, Bomford J and Mott JC (1988) Photoperiod: an important regulator of plasma prolactin concentrations in fetal lambs during later gestation Quarterly Journal of Experimental Physiology 73 241-244

Bassett JM, Curtis N, Hanson C and Weeding CM (1989) Effects of altered photoperiod or maternal melatonin administration on plasma prolactin concentrations in fetal lambs Journal of Endocrinology 122 633-643

Brown WB and Forbes JM (1980) Diurnal variations of plasma prolactin in growing sheep under two lighting regimens and the effect of pinealectomy Journal of Endocrinology $8491-99$

Curlewis JD (1992) Seasonal prolactin secretion and its role in seasonal reproduction: a review Reproduction Fertility and Development 4 1-23

Kennaway DJ, Gilmore TA and Seamark RE (1982) Effect of melatonin feeding on serum prolactin and gonadotrophin levels and the onset of seasonal estrous cyclicity in sheep Endocrinoloogy 110 1766-1772

Krause DN and Dubocovich ML (1990) Regulatory sites in the melatonin system of mammals Trends in Neuroscience 13 464-470

Lincoln GA (1990) Correlation with changes in horn and pelage, but not reproduction, of seasonal cycles in the secretion of prolactin of wild, feral and domesticated breeds of sheep Journal of Reproduction and Fertility 90 286-296

Lincoln GA and Clarke IJ (1994) Photoperiodically induced cycles in the secretion of prolactin in hypothalamo-pituitary disconnected rams: evidence for translation of the melatonin signal in the pituitary gland Journal of Neuroendocrinology $6251-260$

McMillen IC and Nowak R (I989) Maternal pinealectomy abolishes the diurnal rhythm in plasma melatonin concentrations in the fetal sheep and pregnant ewe during late gestation Journal of Endocrinology 120 459-464

McMillen IC, Thorburn GD and Walker DW (1987) Diurnal variations in plasma concentrations of cortisol, prolactin, growth hormone and glucose in the fetal sheep and pregnant ewe during late gestation Journal of Endocrinology 114 65-72

McMillen IC, Walker DW, Young IR and Nowak R (1991) A daily prolactin rhythm persists in the ewe, foetus and newborn lamb after maternal pinealectomy in late gestation Journal of Neuroendocrinology 3 369-374
Maxwell CA, Rintoul AJ, Foldes A, Downing JA, Scaramuzzi RJ and Cester NJ (1989) Seasonal modification of ovine pineal function. 2. Steroidal effects on melatonin and prolactin profiles Neuroendocrinology 50 274-279

Merei JJ, Rao A, Clarke IJ and McMillen IC (1993) Proopiomelanocortin, prolactin and growth hormone messenger ribonucleic acid levels in the fetal sheep pituitary during late gestation Acta Endocrinologica 129 263-267

Morgan PJ, Williams LM, Davidson G, Lawson W and Howell E (1989) Melatonin receptors on ovine pars tuberalis: characterization and autoradiographical localization Journal of Neuroendocrinology 1 1-4

Morgan PJ, King TP, Lawson W, Slater D and Davidson G (1991) Ultrastructure of melatonin-responsive cells in the ovine pars tuberalis Cell and Tissue Research 263 529-534

Poulton AL, English J, Symons AM and Arendt J (1986) Effects of various melatonin treatments on plasma prolactin concentrations in the ewe Journal of Endocrinology 108 287-292

Seron-Ferre M, Vergara M, Parraguez VH, Riquelme R and Llanos AJ (1989) The circadian variation of prolactin in fetal sheep is affected by the seasons Endocrinology 125 1613-1616

Thomas GB, Cummins JT, Cavanagh L and Clarke IJ (1986) Transient increase in prolactin secretion following hypothalamo-pituitary disconnection in ewes during anoestrus and the breeding season Journal of Endocrinology 111 425-431

Wittkowski WH, Schulze-Bonhage AH and Bockers TH (1992) The pars tuberalis of the hypophysis: a modulator of the pars distalis? Acta Endocrinologica 126 285-290

Yellon SM and Longo LD (1987) Melatonin rhythms in fetal and maternal circulation during pregnancy in sheep American Journal of Physiology 252 E799-E802

Yellon SM and Longo LD (1988) Effect of matemal pinealectomy and reverse photoperiod on the circadian melatonin rhythm in the sheep and fetus during the last trimester of pregnancy Biology of Reproduction 39 1093-1099

Zemdegs IZ, McMillen IC, Walker DW, Thorburn GD and Nowak R (1988) Diurnal rhythms in plasma melatonin concentrations in the fetal sheep and pregnant ewe during late gestation Endocrinology 123 284-289 